\title{
VOLKMANN'S ISCHAEMIC CONTRACTURE FOLLOWING ACUTE COMPARTMENT SYNDROME-A CASE REPORT
}

\author{
J. Kingori, MBChB, MMed (Ortho). Consultant, Orthopaedic Surgeon, PCEA Kikuyu Hospital, P.O Box 1010, Kikuyu, \\ Kenya and L. N. Gakuu, MBChB, MMed, Department of Orthopaedic Surgery,University of Nairobi, P.O Box 19676- \\ 00202, Nairobi, Kenya
}

Correspondence to: Dr. J. Kingori, PCEA Kikuyu Hospital, P.O Box 1010, Kikuyu, Kenya. Email:johnkingori@gmail.com

\section{ABSTRACT}

\begin{abstract}
Background: Compartment syndrome involving the extremities is one of orthopaedic emergencies. If not well managed it can lead to serious damage to soft tissues rendering the limb non functional. Design: A case report Setting: PCEA Kikuyu hospital

Methods: An eight year old boy was treated and followed up after he had suffered compartment syndrome on his left forearm. This occurred after he fell and sustained fractures of both radius and ulnar. He was put in a cast at a peripheral hospital.
\end{abstract}

\section{INTRODUCTION}

Compartment syndrome may be defined as a condition in which the circulation within a closed compartment is compromised by an increase in pressure within the compartment resulting in tissue death. The causes of compartment syndrome include crush injuries such as wringer injuries; prolonged external pressure; internal bleeding, especially after injury to a person with haemophilia; fractures; excessive exercise; burns; and intra-arterial injections of drugs or sclerosing agents.

The diagnosis of acute compartment syndrome is confirmed by demonstrating an increase in compartmental pressures. The correlation of the clinical findings with the pressure measurements is dependable. A higher pressure is a strong indication that fasciotomy should be recommended. When one is in doubt it is advisable to release the compartment (1). Other studies have shown that compartment pressures return to normal after a fasciotomy (2).

When compartment pressures are elevated, especially in acute settings, prompt surgical evaluation should be performed, since elevated pressures can,over a prolonged period, cause irreversible damage $(3,4)$.ja vascript:showcontent('active','references'); The exact pressure at which a fasciotomy may be performed is somewhat debatable (5-8).

Javascript show content ('active,',references'); Compartment syndrome is the usual cause of Volkmann's contracture. This case highlights a late clinical presentation and outcome of this disabling condition and reviews the current literature.
Case Report: We present an 8 year old African boy who fell from a height on the $2^{\text {nd }}$ June 2006 . He did sustain closed fractures of the left radius and ulnar bones. He was attended to at a peripheral hospital and the right diagnosis made. Manipulation to reduce the fracture was done on the same day and a long arm cast applied. The child went home but the mother did notice that he was in a lot of pain. She did took him back to the hospital the next day.

The child was admitted for observation. Pain did not subside. The cast was removed on the third day post injury. It was noted that the child's forearm was bad with a big wound and exposed bones. Dressings of the wound were done but with no improvement.

The Child was then referred to PCEA Kikuyu Orthopaedic and Rehabilitation Centre on $27^{\text {th }}$ February 2006. On arrival it was noted that:

- There was an open fracture of the left radius/ ulnar. The wound measured 4 by $10 \mathrm{~cm}$ on the mid-forearm more on the dorsal aspect. It was septic with necrotic tissue. About $2 \mathrm{~cm}$ of both forearm bones was exposed. This affected both proximal and distal fragments.

- The radial pulse was absent. There was however a good capillary refill.

- There was no recordable motor/sensory function of the radial, median and ulnar nerve distal to the elbow clinically.

The boy's mother was counseled on an above elbow amputation but she declined. Vigorous debridement and dressing of the wound was done. An external fixator was applied to facilitate the dressings. 
Physical therapy was done to maintain joint motion on the elbow, wrist and the hand. Skin grafting of the wound was done on $1^{\text {st }}$ April 2006. It took well. The external fixator was removed on $20^{\text {th }}$ April 2006. A long arm cast was applied.

There was mulunion of the bones. Corrective osteotomy and k-wire fixation to align the bones was done on $22^{\text {nd }}$ December 2009.

\section{Currently:}

- All the wounds are healed.

- There is no motor/sensory nerve function distal to the elbow.

- The wrist joint is stiff in dorsiflexion (15 degress). Metarcarpal joints are held in flexion (10degrees)

- The interphalangeal joints are also stiff at 130 degrees of flexion.

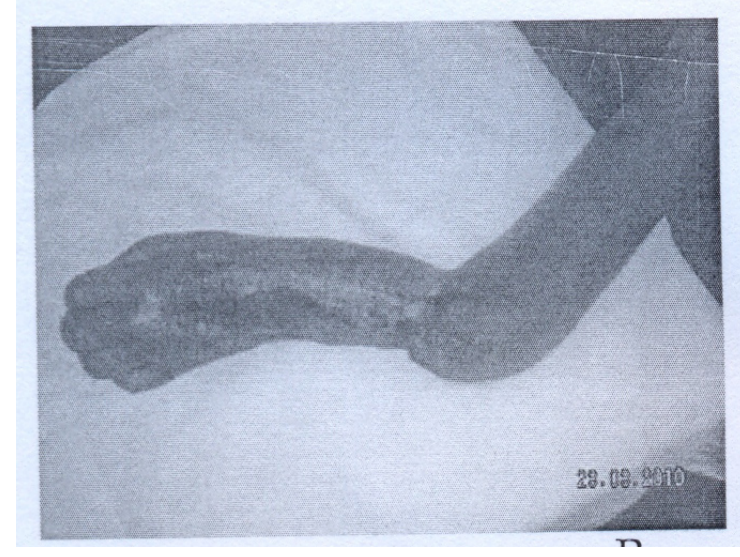

Figure 1:The affected limb

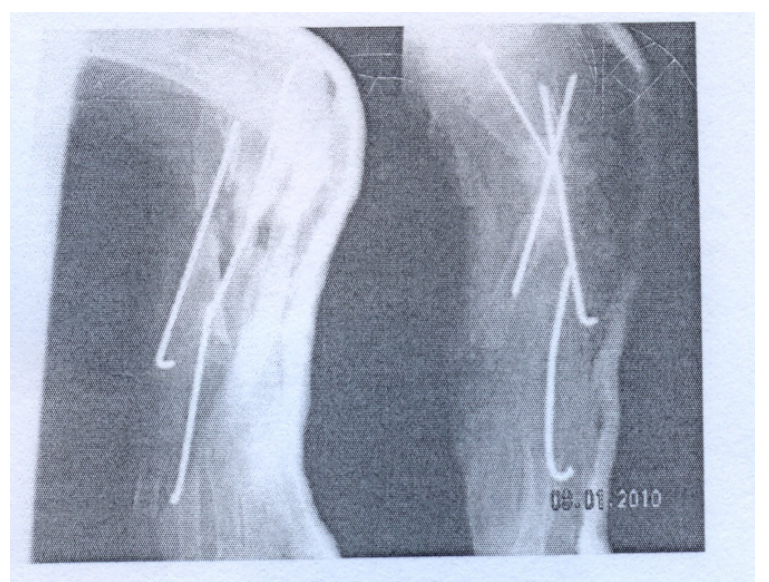

Figure 2: Attempted corrective osteotomy with K-wire fixation to get the forearm bones straight.

\section{DISCUSSION}

Compartment syndrome is a medical term which refers to the compression of nerves, blood vessels and muscle inside a closed space (compartment) within the body. This leads to tissue death due to lack of oxygenation as the blood vessels are compressed by the raised pressure within the compartment. Compartment syndrome most commonly involves the forearm and lower leg. Acute compartment syndrome refers to acute ischaemia of the muscles and nerves within a compartment due to elevated intra-compartmental pressure.

In 1881 Volkmann stated that the paralytic contractures that could develop in only a few hours after injury were caused by arterial insufficiency or ischaemia of the muscles (9). In 1872 he documented about nerve injury and subsequent contracture from compartment syndrome following supracondylar fracture (10).

The signs and symptoms of compartment syndrome include the following:

- Pain (out of proportion to what one would expect, especially with passive stretch of the muscles). This is the most common complaint.

- Firmness of compartment

- Paresthesia

- Paralysis

- Pallor (pale colour)

- Poikilothermia (cold distal extremity compared to the contralateral side)

- Pulselessness

The normal mean interstitial tissue pressure is near zero in non-contracting muscle. If this pressure becomes elevated to $30 \mathrm{mmHg}$ or more, small vessels in the tissue become compressed, which leads to reduced nutrient blood flow, ischaemia and pain. Various recommendations of the intracompartmental pressure are used with some sources quoting $>30 \mathrm{mmHg}$ as an indication for fasciotomy while others suggest a $<30 \mathrm{mmHg}$ difference between intracompartmental pressure and diastolic blood pressure.

Acute compartment syndrome is a medical emergency requiring immediate surgical treatment, known as a fasciotomy, to allow the pressure to return to normal (11).In this case the early signs and symptoms were not picked and fasciotomy was not done.

The outcome after compartment syndrome has set in depends on both the diagnosis and the time from injury to intervention. There is almost complete recovery of limb function if fasciotomy is performed within 6 hours (12). Matsen et al found necrosis after 6 hours of ischaemia. This is currently the accepted upper limit of viability (13). 
Compartment syndrome most commonly occurs on the forearm and the leg on the extremities. Forearm fractures accounted for $22 \%$ of the contractures reported in 1967 by Eichler and Lipscomb (14) and for $15 \%$ reported by Mubarak and Carroll in 1979 (15).

In this particular case it is a severe volkmann's ischeamic contracture according to Tsuge classification (16). Not much of reconstructive surgery is possible.

If an early intervention had been done most probably the limb would have been saved. Patient and parent education on the dangers of plaster of Paris is paramount. The patient will report to the doctor early for something useful to be done. Medical personnel need to be familiar with this devastating condition.

\section{REFERENCES}

1. Crenshaw, A.H., et al. Volkmann's contracture and compartment syndromes, Campbell's. Operative Orthopaedics. Eighth edition: 1992; 3341-3351.

2. Detmer, D.E., Sharpe, K., Sufit, R.L., et al. Chronic compartment syndrome: diagnosis, management, and outcomes. Am.J.Sports Med. 1985; 13(3): 162-170.

3. Pollak, A.N. Use of negative pressure wound therapy with reticulated open cell foam for lower extremity trauma. J. Orthop. Trauma. 2008; 22(10 Suppl): S142S145.

4. Brey, J.M. and Castro, M.D. Salvage of compartment syndrome of the leg and foot. Foot Ankle Clin. 2008; 13(4): 767-772.

5. Blackman, P.G. A review of chronic exertional compartment syndrome in the lower leg. Med. Sci. Sports Exerc. 2000; 32(3 Suppl): S4-S10.
6. Howard, J.L., Mohtadi, N.G. and Wiley, J.P. Evaluation of outcomes in patients following surgical treatment of chronic exertional compartment syndrome in the leg. Clin. J. Sport Med.2000; 10(3): 176-184.

7. Mouhsine, E., Garofalo, R., Moretti, B., et al. Two minimal incision fasciotomy for chronic exertional compartment syndrome of the lower leg. Knee Surg. Sports Traumatol Arthrosc. 2006; 14(2): 193-197.

8. Schepsis, A. A., Martini D. and Corbett M. Surgical management of exertional compartment syndrome of the lower leg. Long-term followup. Am. J. Sports Med.1993;21(6): 811-817.

9. Volkmann R. Die ischaemischen Muskellahmungen und Kontrakturen. Zentralbl. Chir. 1881; 8: 801.

10. Volkmann, R. Verletzungen and Krannkheiten der bewwgungsorgane. In: Handbuch der Allegemeinen und Speziellen Chirurgie. 1872; 2: 234-920.

11. Salcido, R., Lepre, S.J. "Compartment syndrome: wound care considerations". Adv Skin Wound Care. 2007; 20 (10): 559-565.

12. Rorabeck, C.H. and Macnab, I. The pathophysiology of the anterior tibial compartmental syndrome. Clin. Ortho. 1975; (113): 52-57.

13. Matsen, F.A., Winguist, R.A. and Krugmire, R.B. Diagnosis and management of compartmental syndromes. J. Bone Joint Surg. Am. 1980; 62(2): 286-291.

14. Eichler, G.R. and Lipscomb, P.R. The changing treatment of Volkmann's ischemic contractures from 1955 to 1965 at the Mayo Clinic. Clin. Ortho. 1967; 50: 215.

15. Mubarak, S.J. and Carroll, N.C. Volkmann's contracture in children: aetiology and prevention. J. Bone Joint Surg. 1979; (61-B): 285.

16. Tsuge, K. Treatment of established Volkmann's contracture. J. Bone Joint Surg. 1975; 57-A: 925. 